\title{
Surface Molecularly Imprinted Nanowires for Biorecognition
}

\author{
Huang-Hao Yang ${ }^{*}$, , Shu-Qiong Zhang ${ }^{\ddagger}$, Fang $\operatorname{Tan}^{\ddagger}$, Zhi-Xia Zhuang ${ }^{\dagger, \ddagger}$, \\ Xiao-Ru Wang ${ }^{\dagger, \ddagger}$ \\ The Key Laboratory of Analytical Sciences of MOE, Department of Chemistry, \\ Xiamen University, Xiamen 361005, P.R.China and Material Transport \& \\ Transformation in Environmental \& Life Processes Lab, The First Institute of \\ Oceanography, SOA, Qingdao, 266061, P.R. China
}

Email:hhyang@yanan.xmu.edu.cn

\section{Supporting Information}

\section{Deposit silica nanotubes within the pores of the alumina membranes}

TEOS $2 \mathrm{~mL}$ was added to a mix solution of $19 \mathrm{~mL}$ ethanol and $1 \mathrm{~mL}$ acetate buffer ( $0.1 \mathrm{~mol} / \mathrm{L}, \mathrm{pH}=5.1)$. The resulting solution was stirred for $5 \mathrm{~min}$, before the alumina membrane was immersed. The silanization reaction was terminated after 10 min by rinsing the membrane with ethanol. The membrane was then cured in an oven at $150{ }^{\circ} \mathrm{C}$ for $1 \mathrm{~h}$. Note that the surfaces of the membrane are coated with thin silica films, which are removed by a brief mechanical polish.

\section{Modification of membranes containing $\mathrm{SiO}_{2}$ nanotubes}

Freshly made alumina membranes containing $\mathrm{SiO}_{2}$ nanotubes were immersed into an ethanol-based solution containing $5 \%$ acetate buffer $(0.1 \mathrm{~mol} / \mathrm{L}, \mathrm{pH}=5.1), 5 \%$ trimethoxysilylpropyl aldehyde and $5 \%$ TEOS. The resulting aldehyde-modified membranes were then rinsed with ethanol and dried for 24 hours in an $\mathrm{N}_{2}$-filled box.

\section{Binding of glutamic acid to the walls of the silica nanotubes}

The aldehyde-modified nanotubes membranes were incubated for $24 \mathrm{~h}$ at room temperature with a solution of glutamic acid in carbonate buffer. The glutamic acid modified membranes were then thoroughly rinsed with water and ethanol, and dried for 24 hours in an $\mathrm{N}_{2}$-filled box.

\section{Preparation of surface imprinted polypyrrole nanowires}

The glutamic acid containing membranes were immersed for $1 \mathrm{~h}$ in a cooled $0.2 \mathrm{M}$ aqueous pyrrole solution (containing $0.2 \mathrm{M} \mathrm{NaAc}$ ), prepared from freshly distilled pyrrole. An equal volume of cooled oxidant solution (0.2 $\mathrm{M}$ iron chloride) was then added. The mixture was left for polymerization for $12 \mathrm{~h}$. Polypyrrole preferentially nucleates and grows on the pore wall. The surface layers of polypyrrole on alumina membrane were removed by polishing the alumina membrane faces with $1 \mu \mathrm{m}$ alumina powder. The membrane was then ultrasonicated in water to remove the alumina powder. Figure S1 is the EDS result of polypyrrole nanowires after the removal of alumina template membranes and the silica nanotubes. 


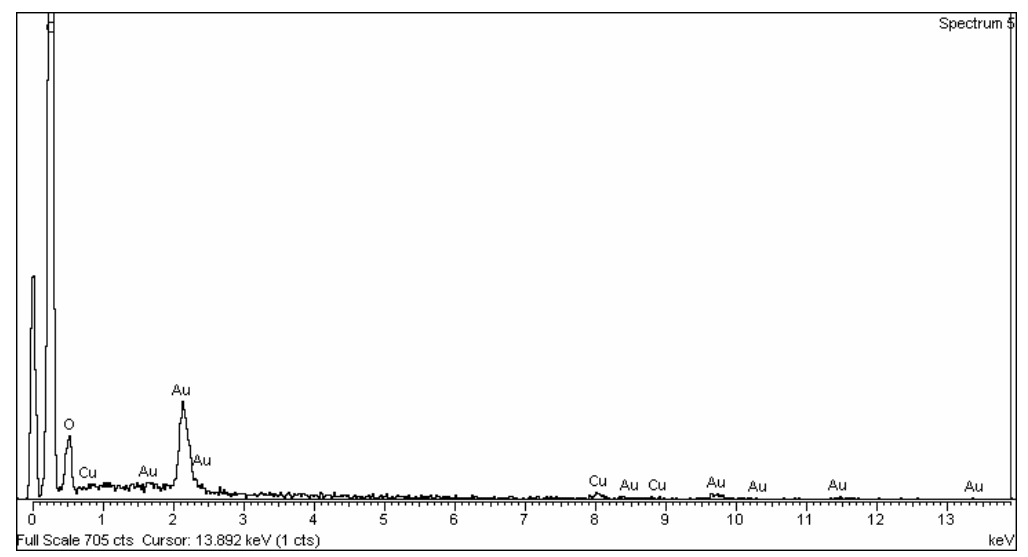

Figure S1 EDS result of polypyrrole nanowires

\section{Overoxidation of imprinted polypyrrole nanowires}

The alumina membrane was firstly dissolved with dilute phosphoric acid. The resulting polypyrrole nanowires with silica nanotubes at surface were then dispersed in aqueous $0.1 \mathrm{M} \mathrm{NaOH}$ and further overoxidized at $+1.5 \mathrm{~V}$ vs $\mathrm{Ag} \mid \mathrm{AgCl}$ (saturated $\mathrm{KCl})$ with a flow-through electrolysis cell, which was designed by Nagaoka, at a flow rate of $0.25 \mathrm{~mL} / \mathrm{min}$. At last, the imprinted overoxidized polypyrrole nanowires were isolated by dissolving the residual silica with HF solution, and purified by repeated centrifugation and washing with water and ethanol. (Caution: Proper precautions should be exercised when handling HF. It is highly corrosive, toxic, and in extreme circumstances can lead to skin grafts, amputation, or death). Concentration of the nanowires was evaluated by measuring the weight of the nanowires after drying for $24 \mathrm{~h}$ at $70{ }^{\circ} \mathrm{C}$.

(Reference: Okuno, H.; Kitano, T.; Yakabe, H.; Kishimoto, M.; Deore, B. A.; Siigi, H.; Nagaoka, T. Anal. Chem. 2002, 74, 4184)

\section{Steady-state Binding Experiment}

The imprinted nanowires were suspended in water and appropriate volumes were added into $1.5 \mathrm{~mL}$ test-tubes, followed by glutamic acid, $\mathrm{pH} 1.7 \mathrm{KCl}-\mathrm{HCl}$ buffer, and water to give a total volume of $1 \mathrm{~mL}$. The glutamic acid concentration is $2.5 \times 10^{-4}$ $\mathrm{mol} / \mathrm{L}$. The samples were incubated on a rocking-table for $1 \mathrm{~h}$ at room temperature. After removal of the nanowires by ultrafiltration, the $\mathrm{pH}$ of the filtered solution was adjusted to 9.1 with a borate buffer, and o-phthalaldehyde (OPA) and 3-mercaptopropionic acid were then added to the solution (OPA, $0.35 \mathrm{mM}$ and 3-mercaptopropionic acid, $0.62 \mathrm{mM}$ ). The fluorescence from the amino acid-OPA product was recorded with a Hitachi F-2500 fluorescence spectrometer at $458 \mathrm{~nm} 10$ min after mixing.

Selective for glutamic acid over phenylalanine and arginine

\begin{tabular}{ccc}
\hline \multicolumn{3}{c}{ Selective ability of the imprinted nanowires ${ }^{a, b}$} \\
\hline Glutamic acid & phenylalanine & arginine \\
$47.2 \mathrm{nmol}$ & $3.86 \mathrm{nmol}$ & $4.05 \mathrm{nmol}$ \\
\hline${ }^{a}$ Experiment was conducted by the addition of $1 \mathrm{mg}$ of nanowires in $2.5 \times 10^{-4} \mathrm{~mol} / \mathrm{L}$ amino acid \\
$(1 \mathrm{~mL})$ solution at $\mathrm{pH} 1.7$ at room temperature. ${ }^{b}{ }^{n}=3$
\end{tabular}




\section{Kinetic Binding Profile}

The imprinted nanowires were suspended in water. An appropriate volume of the suspension were added into $1.5 \mathrm{~mL}$ test-tubes, followed by glutamic acid, $\mathrm{pH} 1.7$ $\mathrm{KCl}-\mathrm{HCl}$ buffer, and water to give a total volume of $1 \mathrm{~mL}$. The glutamic acid concentration was $2.5 \times 10^{-4} \mathrm{~mol} / \mathrm{L}$, and the nanowires concentration was $1 \mathrm{mg} / \mathrm{mL}$. The samples were incubated on a rocking-table. After removal of the nanowires by ultrafiltration, the target molecule in the filtrate was determined by o-phthalaldehyde fluorometry.

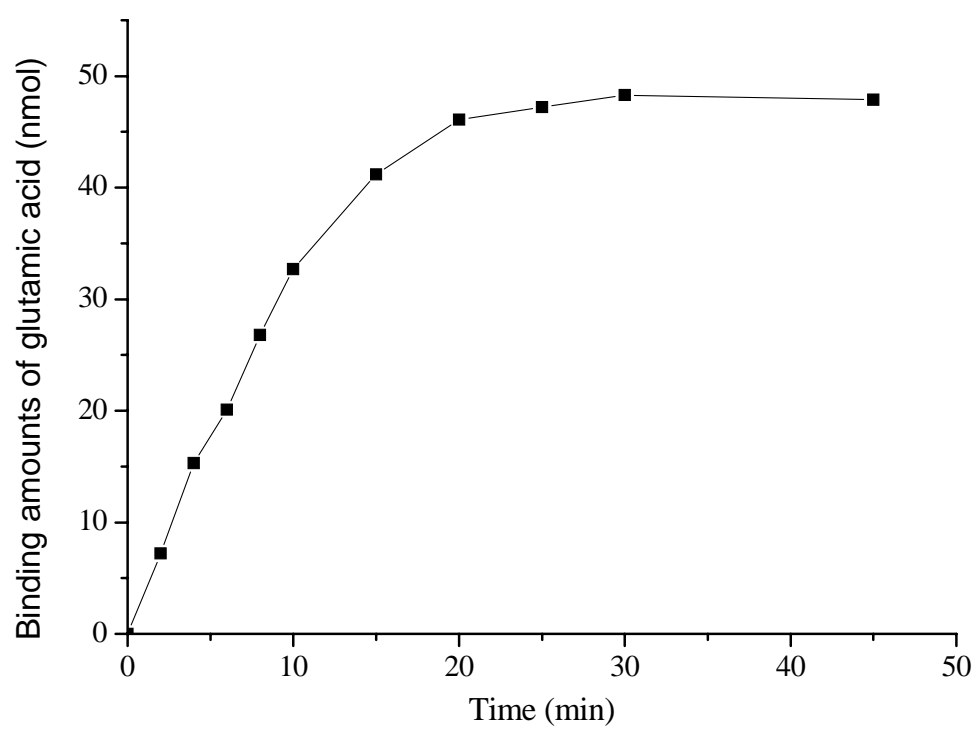

Figure S2. Kinetic binding profile of glutamic acid binding to the molecularly imprinted nanowires 